\title{
CADMIUM BLOOD CONCENTRATIONS IN RELATION TO NUTRITION
}

\author{
Marica Krajčovičová-Kudláčková1, Monika Ursínyovái ${ }^{1}$, Vlasta Mašánová ${ }^{1}$, Alžbeta Béderová2, \\ Martina Valachovičová ${ }^{1}$ \\ ${ }^{1}$ Slovak Medical University, Institute of Preventive and Clinical Medicine, Bratislava, Slovak Republic \\ ${ }^{2}$ Regional Institute of Public Health, Bratislava, Slovak Republic
}

\begin{abstract}
SUMMARY
Cadmium is a toxic element ubiquitous in the environment, which damages biological systems in various ways. The major source of cadmium exposure is food. High cadmium content in the soil leads to high cadmium concentrations in certain plants such as grains (above all surface layers and germs), oil or non-oil seeds, fruit and vegetables. These food commodities are the crucial components of a vegetarian nutrition. Blood cadmium concentrations were measured in two non-smoking population groups: the vegetarian group $(n=80)$ and the non-vegetarian (control) group of general population on traditional mixed diet $(n=84)$. The significantly higher blood cadmium content $(1.78 \pm 0.22 \mathrm{vs} .0 .45 \pm 0.04 \mu \mathrm{g} / \mathrm{l})$ was measured in vegetarian group. Healthy risk values $>5 \mu \mathrm{g} / \mathrm{l}$ were found in 6 vegetarians vs. no non-vegetarian. The highest cadmium concentration $(3.15 \pm 0.77$ $\mu \mathrm{g} / \mathrm{l})$ was measured in vegan subgroup (plant food only, $n=10$ ) and that value decreased with increasing animal food consumption (1.75 \pm 0.36 $\mu \mathrm{g} / \mathrm{l}$, lactovegetarian and lactoovovegetarian subgroup /added dairy products and eggs, $n=41 /, 1.34 \pm 0.21 \mu \mathrm{g} / \mathrm{l}$, semivegetarian subgroup las a previous subgroup and added white meat, $n=29 /)$. Risk vegetarians vs. non-risk vegetarians consume significantly higher amounts of whole grain products, grain sprouts and oil seeds. Blood cadmium content is directly influenced by age $(r=0.32, p<0.001)$, by whole grain product intake $(r=0.66, p<0.001)$ and by duration of vegetarianism $(r=0.5, p<0.001)$. Oxidative stress plays a major role in chronic cadmium induced hepatic and renal toxicity as well as in other consequences of cadmium injuries. Vegetarians have significantly higher plasma concentrations of natural antioxidants. The sufficient antioxidative protection against cadmium induced free radical formation in vegetarians may inhibit the harmful effects of greater cadmium intake from plant food.
\end{abstract}

Key words: cadmium, nutrition, vegetarians

Address for correspondence: Marica Kudláčková, Slovak Medical University, Limbová 12, SK-833 03 Bratislava, Slovak Republic. E-mail: marica.kudlackova@szu.sk

\section{INTRODUCTION}

Cadmium is an ubiquitous environmental toxicant and known carcinogen with an extremely long biological half-life of 10-30 years in humans. This toxic element affects biological systems in various ways $(1,2)$. Food and tobacco are the major sources of cadmium exposure. High concentrations of cadmium in the soil (use of phosphate fertilizers) combined with low $\mathrm{pH}$ often lead to high cadmium concentrations in plants such as grains. Among the grains, wheat contains the highest cadmium concentration and the concentration is higher in the bran and sprout fractions that in the endosperm (3). The significantly higher total liver cadmium concentration at the end of the experiment in duration of 36 days (82 ng vs. $53.6 \mathrm{ng}$ ) was found in rats consuming an experimental diet with wheat bran (cadmium content $31.2 \mu \mathrm{g} / \mathrm{kg}$ of diet) vs. wheat endosperm (cadmium content $11.3 \mu \mathrm{g} / \mathrm{kg}$ of diet). As a consequence of genetic characteristics, sunflowers (and other oil and non-oil plants) have a propensity to take up cadmium from the soil and deposit it in the kernels (4). Fruit and vegetables can also contain higher amounts of cadmium (5). These findings suggest that a predominant consumption of plant food may represent a higher cadmium intake and the health risks. In the presented study we evaluated blood cadmium concentrations in two non-smoking population groups in relation to their different nutritional habits.

\section{SUBJECTS AND METHODS}

Apparently healthy adult subjects $(\mathrm{n}=164)$ aged $19-60$ years (volunteers of epidemiological study of health benefits or risks of vegetarian nutrition) were distributed into two groups characterized by a different nutrition: the vegetarian group $(n=80)-10$ vegans (plant food only), 41 lactovegetarians and lactoovovegetarians (added dairy products and eggs), 29 semivegetarians [as previous subgroup and added white meat (fish and poultry) consumption] and the non-vegetarian (control) group $(n=84)$ - subjects of general population on a traditional mixed diet. Characteristics of groups are showed in Table 1. All subjects were non-smokers from the same region (Bratislava and surroundings).

The cadmium concentrations in whole blood were estimated by graphite furnace atomic absorption spectrometry (6). A Seronorm TM Trace Elements, whole blood (1) was used as a reference material (Nycodem Pharma AS, Norway). Conjugated dienes of fatty acids in plasma were estimated by spectrophotometric method (7). EDTA was used as an anticoagulant and as an inhibitor of free radical reactions. Daily intake of selected food commodities was calculated from dietary questionnaires. The questionnaire contained 114 food items. The frequency of consumption was measured using four categories: almost never, times per day, per 
Table 1. Characteristic of groups, cadmium blood concentrations [in $\mu \mathrm{g} / \mathrm{l}]$ and daily intake of selected food

\begin{tabular}{|c|c|c|}
\hline & Vegetarians & Non-vegetarians \\
\hline$n(m+f)$ & $80(41+39)$ & $84(47+37)$ \\
\hline Age range $[\mathrm{y}]$ & $19-60$ & $19-59$ \\
\hline Average age [y] & $35.9 \pm 1.5$ & $36.3 \pm 1.3$ \\
\hline Body mass index $\left[\mathrm{kg} / \mathrm{m}^{2}\right]$ & $22.0 \pm 0.3$ * & $24.1 \pm 0.4$ \\
\hline Duration of vegetarianism [y] & $6.43 \pm 0.39$ & - \\
\hline Smokers & 0 & 0 \\
\hline Cadmium blood concentration distribution & $1.78 \pm 0.22$ & $0.45 \pm 0.04$ \\
\hline$<1$ & $51 \%$ & $95 \%$ \\
\hline $1-2$ & $19 \%$ & $3 \%$ \\
\hline$>2-3$ & $10 \%$ & $2 \%$ \\
\hline$>3-4$ & $7 \%$ & $0 \%$ \\
\hline$>4-5$ & $5 \%$ & $0 \%$ \\
\hline$>5$ & $8 \%$ & $0 \%$ \\
\hline Vegans $(n=10)>5$ & $3.15 \pm 0.7730 \%$ & \\
\hline Vegetarians $(n=41)>5$ & $1.75 \pm 0.367 \%$ & \\
\hline Semivegetarians $(n=29)>5$ & $1.34 \pm 0.210 \%$ & \\
\hline \multicolumn{3}{|l|}{ Intake of selected food [g per day] } \\
\hline Whole grain products & $203 \pm 3$ * & $87 \pm 2$ \\
\hline Grain sprouts & $1.4 \pm 0.2$ * & 0 \\
\hline Oil seeds & $15.8 \pm 0.5$ * & 0 \\
\hline Pulses & $40.8 \pm 1.3$ * & $8.4 \pm 0.6$ \\
\hline
\end{tabular}

Results are expressed as mean \pm SEM * $p<0.001 ; n$ - number; $m$ - males; $f$ - females

week or per month depending on food item. The probands used household measures. Trained workers checked the completeness of questionnaires. The survey was carried out in spring. Intake of vitamins, mineral and trace elements was considered only in their natural form (no supplementation). Student's t-test and regression analysis were used for final evaluation.

\section{RESULTS AND DISCUSSION}

The significantly higher mean blood cadmium concentration was found in vegetarian group (Table 1) in comparison to nonvegetarian group $(1.78 \mathrm{vs}$. $0.45 \mu \mathrm{g} / \mathrm{l})$. The highest measured vegetarian value was $10.48 \mu \mathrm{g} / 1 \mathrm{vs} .2 .27 \mu \mathrm{g} / \mathrm{l}$. In our previous study (8), the mean cadmium blood concentration in a group of vegetarian children and adolescents $(\mathrm{n}=53)$ was $1.05 \mu \mathrm{g} / \mathrm{l}$ with maximal measured value $3.9 \mu \mathrm{g} / 1$. These results in connection with data of long biological half-life suggest a logical assumption that the accumulation of cadmium increases with age. A significant positive linear correlation between cadmium concentration and age we describe in the presented study of adult population (Fig.1).

The medium blood cadmium concentrations in Czech urban population (30 cities) were measured in the interval $0.9-0.4 \mu \mathrm{g} / \mathrm{l}$ in 1994-2003 (9). Blood cadmium concentration (medium) $0.7 \mu \mathrm{g} / \mathrm{l}$ was found in 1,216 adult blood donors (10). The concentration of cadmium had a decreasing trend for the years 1975-1999 (from
$0.82 \mu \mathrm{g} / 1$ to $0.47 \mu \mathrm{g} / \mathrm{l}$ ) in the adult Czech population (11). Our results of cadmium blood concentration in Slovak non-vegetarian non-smoking adult population from region Bratislava correspond with mean cadmium blood values in Czech population. It is known that smoking habits affect cadmium concentrations in blood. The increasing mean values of blood cadmium with number of cigarettes smoked per day were described (12): $0.40 \mu \mathrm{g} / \mathrm{l}$ in nonsmoking group of 406 subjects of Czech general population vs. $1.32 \mu \mathrm{g} / 1,2.10 \mu \mathrm{g} / 1,2.55 \mu \mathrm{g} / 1$ in groups smoking less that 10 , $10-20$, more that 20 cigarettes per day $(n=203)$.

As denoted in the first chapter, the content of cadmium in plant food such as whole grain products, grain sprouts, oil and non-oil seeds, fruit and vegetables is higher in comparison to animal food. These food commodities are the crucial components of a vegetarian nutrition (Table 1) (13). As showed in Fig.1, cadmium blood concentrations significantly increase with consumption of whole grain products. The cadmium levels above $5 \mu \mathrm{g} / 1$ represent the health risks (14). Risk cadmium values were found in 6 vegetarians ( $8 \%$ ) (Table 1, Fig. 1). Alternative nutrition subjects with established risk cadmium values consume higher amount of whole grain products (200-350 g/day - Fig.1) as well as other cadmium richer food (Table 2). The significantly higher consumption of whole grain products, grain sprouts and oil seeds in 6 risk vegetarians vs. 74 vegetarians with "healthy provisional tolerable" values of blood cadmium concentration is introduced in Table 2. Duration of vegetarianism in 6 risk vegetarians was 7-15 years (Fig.1), mean value 11.33 years vs. 6.08 years in 
Table 2. Cadmium blood concentration, lipoperoxidation product and daily intake of selected food in groups vegetarians with risk vs. non-risk cadmium blood concentrations

\begin{tabular}{|c|c|c|}
\hline & \multicolumn{2}{|c|}{ Vegetarians } \\
\hline & $\begin{array}{l}\text { cadmium } \\
>5 \mu \mathrm{gll}\end{array}$ & $\begin{array}{c}\text { cadmium } \\
<5 \mu \mathrm{gll}\end{array}$ \\
\hline $\mathrm{n}$ & 6 & 74 \\
\hline Average age [y] & $40.3 \pm 0.9$ & $35.5 \pm 1.4$ \\
\hline Duration of vegetarianism [y] & $11.33 \pm 1.36$ & $6.08 \pm 0.37$ \\
\hline Cadmium blood concentration $[\mu \mathrm{g} / \mathrm{l}]$ & $7.38 \pm 0.81$ * & $1.31 \pm 0.14$ \\
\hline Conjugated dienes of fatty acids $[\mu \mathrm{mol} / \mathrm{l}]$ & $2.02 \pm 0.22$ & $1.57 \pm 0.12$ \\
\hline \multicolumn{3}{|l|}{ Intake of selected food [g per day] } \\
\hline Whole grain products & $305 \pm 12$ * & $193 \pm 5$ \\
\hline Grain sprouts & $3.7 \pm 0.8^{\wedge}$ & $1.2 \pm 0.2$ \\
\hline Oil seeds & $25.4 \pm 1.3$ * & $15.0 \pm 0.6$ \\
\hline Pulses & $35.2 \pm 2.7$ & $41.2 \pm 1.3$ \\
\hline
\end{tabular}

$\wedge p<0.01 * p<0.001$

risk values of conjugated dienes $>2.4 \mu \mathrm{mol} / \mathrm{l}$

vegetarians with cadmium content below $5 \mu \mathrm{g} / 1$ (Table 2). The relationship of cadmium blood concentration and duration of vegetarianism is significantly positive (Fig.1), equally as in children and adolescents (8).

The studies on mammals have shown that long-term cadmium exposure stimulates formation of reactive oxygen species, which cause lipid peroxidation process $(15,16)$ and damage of other biomolecules (17). Toxic activity of cadmium is exhibited when it is free, when it is not bound to proteins. In all tissues metallothionein plays a protective role in cadmium exposure forming a non-toxic metal protein complex (18). One molecule of metallothionein is capable of binding 7 atoms of cadmium. Tripeptide thiol glutathione also provides a cadmium detoxification (19). The largest amounts of cadmium (75\%) are deposited in the liver and kidneys, in which they cause a hepatotoxicity and a nephrotoxicity. The accumulation and toxicity of cadmium in humans depend on various factors, such as the daily intake, the form of cadmium in food and its multiple interaction with dietary components mainly with calcium, zinc, selenium and iron. These interactions provide a cadmium detoxification and instantly they may cause nutritional deficiencies in organism. Wing and co-workers (3) measured a significantly reduced total cadmium content in rat liver at condition of the high iron status vs. low iron status (50 $\mathrm{ng}$ of cadmium vs. $89.6 \mathrm{ng}$ in case of wheat bran diet; $34.2 \mathrm{ng}$ of cadmium vs. $56.4 \mathrm{ng}$ in case of wheat endosperm diet). Other paper described an inverse correlation between iron status and blood cadmium in humans (20). Interactions between cadmium and calcium in bone may result in disorders of bone metabolism (21). Cadmium exposure inhibits zinc and iron transportation from placenta to fetus as well as copper, calcium, natrium and potassium uptake and transportation across the placenta influencing fetal growth and metabolism (22). Cadmium absorption is reduced by vitamin $\mathrm{C}$. The vitamin $\mathrm{C}$ supplement decreased the carcass cadmium burden and the cadmium content in the liver, kidneys, testicles and muscles (23).
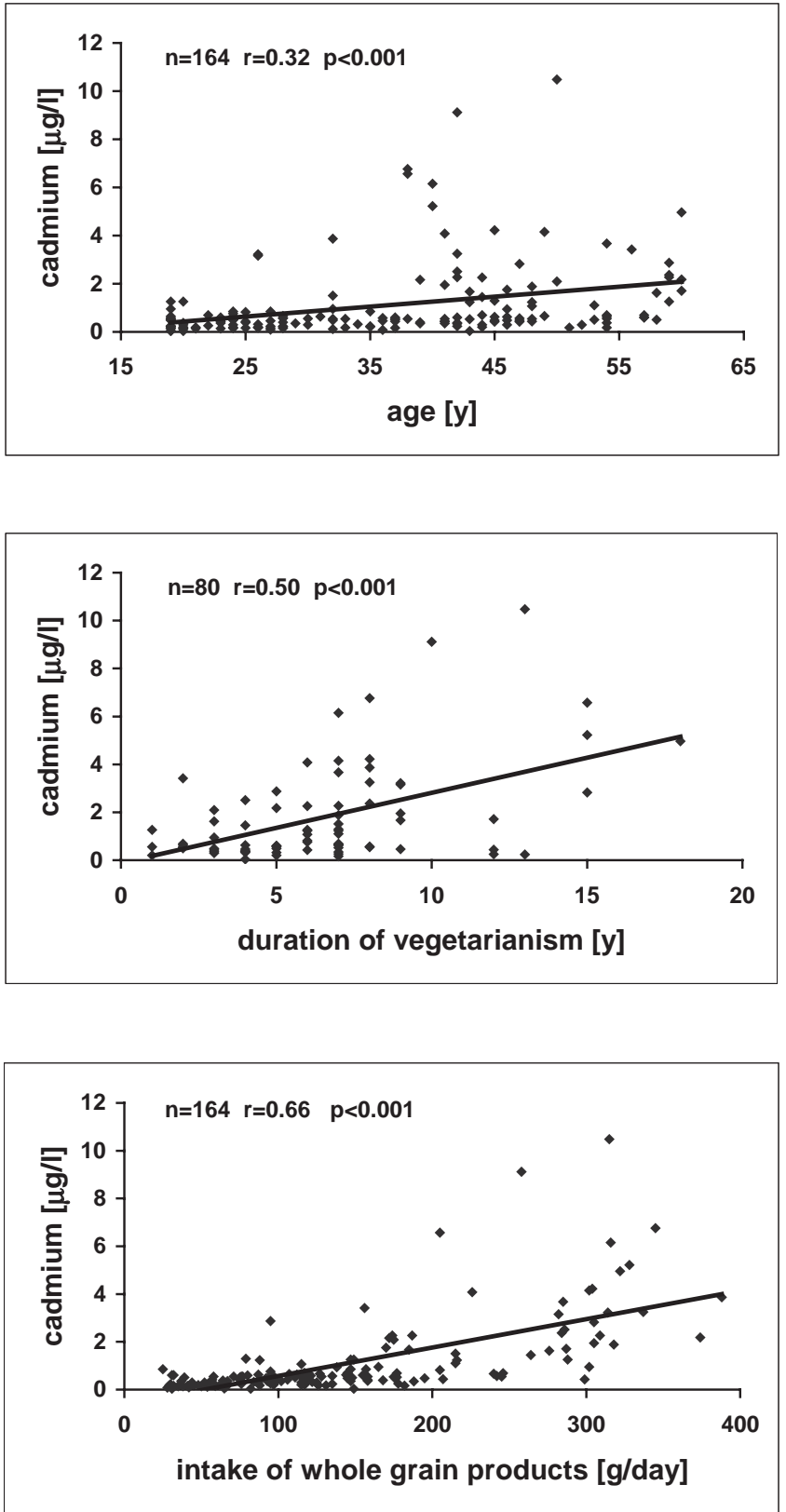

Fig. 1. Relationship between cadmium blood concentrations and age, duration of vegetarianism or intake of whole grain products.

Strict vegetarians - vegans may have a frequent risk of deficiency of iron, calcium and zinc as a consequence of inhibited absorption by phytic acid, oxalic acid and fiber (24). Vegans also suffer from low glutathione content (as a consequence of methionine deficiency) (25). Glutathione provides a first line of defense against cadmium toxicity (19). These facts suggest, that inhibition of cadmium toxicity may be insufficient in this population group. Among the vegetarians, the highest cadmium blood concentrations we ascertained in vegans (Table 1). Cadmium blood content decreases with increasing animal food consumption (Table 1).

Oxidative stress appears to play a major role in chronic cadmium induced hepatic and renal toxicity and other consequences of cadmium injuries. A sufficient antioxidative status may provide the protection against cadmium toxicity $(23,26)$. Vegetarians have significantly higher concentrations of natural antioxidant vitamins 
in comparison to general population $(13,27)$. These vegetarian vitamin values have a maximal antioxidative efficiency (27) and thus a maximal inhibition of free radical effects. The concentrations of lipid peroxidation product (as an indicator of oxidative rate) in group of vegetarians with risk cadmium values vs. vegetarian group with non-risk values are introduced in Table 2. Mean blood cadmium concentration in risk group is 5.6-fold higher than in non-risk group $(7.38$ vs. $1.31 \mu \mathrm{g} / \mathrm{l})$. In spite of the significantly higher blood cadmium concentration as a consequence of a greater cadmium intake from plant food, the sufficient antioxidative status in vegetarians $(13,27)$ inhibits harmful effects of higher free radical production caused by cadmium exposure. The non-significant difference in plasma values of conjugated dienes of fatty acids between risk and non-risk vegetarian groups (both diene values below risk limit; see legend below the table) documents this inhibition.

\section{CONCLUSION}

The significantly higher mean blood cadmium concentration was measured in vegetarian group in comparison to non-vegetarian group. The highest cadmium content was found in vegan subgroup and that value decreased with increasing animal food consumption. Healthy risk values were found in $8 \%$ of vegetarians vs. no non-vegetarian. Cadmium risk vegetarians vs. cadmium non-risk vegetarians consume the significantly higher amounts of whole grain products, grain sprouts and oil seeds. Cadmium blood concentration is directly influenced by age, whole grain product intake and duration of vegetarianism.

\section{REFERENCES}

1. Nordberg GF. Cadmium and health in the 21 st century-historical remarks and trends for the future. Biometals. 2004 Oct;17(5):485-9.

2. Boguszewska A, Pasternak K. Cadmium - influence on biochemical processes of the human organism. Ann Univ Mariae Curie Sklodowska. 2004;59(2):519-23

3. Wing AM, Wing K, Tidehag P, Hallmans G, Sjorstrom R. Cadmium accumulation from diets with and without wheat bran in rats with different iron status. Nutr Res. 1992;12:1205-15.

4. Reeves PG, Vanderpool RA. Cadmium burden of men and women who report regular consumption of confectionery sunflower kernels containing a natural abundance of cadmium. Environ Health Perspect. 1997 Oct;105(10):1098-104.

5. Donma O, Metin Donma M. Cadmium, lead and phytochemicals. Med Hypotheses. 2005;65(4):699-702.

6. Cadmium. In: Angerer J, Schaller KH, editors. Analyses of hazardous substances in biological materials. Vol. 1. Weinheim: Verlagsgesellschaft; 1985. p. 81-92.

7. Recknagel R, Glende EA. Spectrophotometric detection of lipid conjugated dienes. In: Colowick SP, Kaplan NO, editors. Methods in enzymology. New York: Academic Press; 1984. p. 331-7.
8. Krajčovičová-Kudláčková M, Ursínyová M, Hladíková V, Šimončič R, Béderová A, Magálová T, et al. Cadmium blood levels in two groups of children and adolescents with different diets. Cesk Pediatr. 1999;54(9): 482-486. (In Slovak.)

9. Puklová V, Batáriová A, Černá M, Kotlík B, Kratzer K, Melicherčík J, et al. Cadmium exposure pathways in the Czech urban population. Cent Eur J Public Health. 2005 Mar; 13(1):11-9.

10. Beneš B, Spěváčková V, Šmíd J, Čejchanová M, Černá M, Šubrt P, et al. The concentration levels of $\mathrm{Cd}, \mathrm{Pb}, \mathrm{Hg}, \mathrm{Cu}, \mathrm{Zn}$ and $\mathrm{Se}$ in blood of the population in the Czech Republic. Cent Eur J Public Health. 2000;8(2):117-9.

11. Beneš B, Spěváčková V, Čejchanová M, Šmíd J, Švandová E. Retrospective study of concentration levels of $\mathrm{Pb}, \mathrm{Cd}, \mathrm{Cu}$ and $\mathrm{Se}$ in serum of the Czech population in time period 1970-1999. Cent Eur J Public Health 2001;9(4):190-5.

12. Korečková-Sysalová J. Determination of cadmium and lead levels in human blood of a general Czech population by GFAAS. Biol Trace Elem Res. 1997 Mar;56(3):321-9.

13. Krajčovičová-Kudláčková M, Spustová V, Pauková V. Lipid peroxidation and nutrition. Physiol Res. 2004;53(2):219-24.

14. Tietz NW. General clinical tests. In: Tietz NW, editor. Clinical guide to laboratory tests. Philadelphia: WB Saunders Comp; 1995.

15. Kaczmarek-Wdowiak B, Andrzejak R, Skoczynska A, Mlynek V. The effect of chronic exposure to lead and cadmium on lipid peroxidation in the rat brain. Med Pr. 2004; 55(5):403-10. (In Polish.)

16. Krajčovičová-Kudláčková M, Ozdín L'. Effect of fatty acid composition, cadmium and vitamin $\mathrm{E}$ intake on prooxidative-antioxidative state of rat liver. Vet Med. 1995;40(9):293-8.

17. Stohs SJ, Bagchi D. Oxidative mechanisms in the toxicity of metal ions. Free Radic Biol Med. 1995 Feb;18(2):321-36.

18. Klaassen CD, Liu J, Choudhuri S. Metallothionein, an intracellular protein to protect against cadmium toxicity. Annu Rev Pharmacol Toxicol. 1999;39:267-94

19. Kamiyama T, Miyakawa H, Li JP, Akiba T, Liu JH, Liu J, et al. Effects of one-year cadmium exposure on livers and kidneys and their relation to glutathione levels. Res Commun Mol Pathol Pharmacol. 1995 May;88(2):177-86.

20. Barany E, Bergdahl IA, Bratteby LE, Lundh T, Samuelson G, Skerfving $\mathrm{S}$, et al. Iron status influences trace element levels in human blood and serum. Environ Res. 2005 Jun;98(2):215-23.

21. Kazantzis G. Cadmium, osteoporosis and calcium metabolism. Biometals. 2004 Oct;17(5):493-8.

22. Kuriwaki J, Nishijo M, Honda R, Tawara K, Nakagawa H, Hori E, et al. Effects of cadmium exposure during pregnancy on trace elements in fetal rat liver and kidney. Toxicol Lett. 2005 Apr 28;156(3):369-76.

23. Grosicki A. Influence of vitamin $\mathrm{C}$ on cadmium absorption and distribution in rats. J Trace Elem Med Biol. 2004;18(2):183-7.

24. Krajčovičová-Kudláčková M. Health risks of alternative nutrition. Klin Biochem Metab. 2001;9(4):187-93. (In Slovak.)

25. Krajčovičová-Kudláčková M, Babinská K, Valachovičová M. Health benefits and risks of plant proteins. Bratisl Lek Listy. 2005;106(6-7):231-4.

26. Morales AI, Vicente-Sanchez C, Jerkic M, Santiago JM, SanchezGonzalez PD, Perez-Barriocanal F, et al. Effect of quercetin on metallothionein, nitric oxide syntheses and cyclooxygenase-2 expression on experimental chronic cadmium nephrotoxicity in rats. Toxicol Appl Pharmacol. 2006 Jan 1;210(1-2):128-35.

27. Krajčovičová-Kudláčková $M$, Šimončič R, Béderová $A$, Magálová $T$, Grančičová E, Klvanová J. Antioxidative levels in two nutritional population groups. Oncol Rep. 1996;3:1119-23.

Received February 20, 2006 Received in revised form and accepted April 28, 2006 